ranks, they have been encouraged by the approbation of the majority of the profession, and confirmed by the hostility of those who desire, for their own ends, to destroy the colleges, and to erect on their ruins machinery of a much more exclusive description.

The institution of the non-resident fellowship arose out of a desire expressed by many to possess the fellowship of a college at a price considerably reduced, on the ground that they were unable, from distance, to reap its full advantages. It is quite possible, and even probable, that, to many of the practitioners of this country, the fellowship of a college will not be an object of ambition; but it surely is not fair to represent as mercenary a measure guarded as I have explained, in which the projectors have no interests that are not of a public description.

Before concluding this letter, I must inform you that the college has by charter the right, which it has not permitted to lie dormant, of punishing by admonition, by suspension, and, if necessary, by expulsion, any fellow who may wilfully violate its laws by immoral or unprofessional conduct. By applying for the fellowship, therefore, the candidate must be held as one who publicly renounces those discreditable courses which are unhappily so common in these times.

I am, Sir, your obedient servant,

A Fellow of the Royal College of SURGEONS OF EDINBURGH.

Edinburgh, Nov. 1856 .

\section{TREATMENT OF PUERPERAL CONVULSIONS.} To the Editor of THe LaNoET.

SIR,-By way of practical comment upon the remarks which Dr. Tyler Smith makes respecting the treatment of " puerperal convulsions" by bleeding, artificial delivery, and cold applications, in his admirable lecture published in THE LANCE' of the 25th ultimo, permit me to forward to you for publication, if you think proper, the particulars of a case which occurred in my practice some years ago, and which illustrates the sort of treatment I have generally found to be successful in cases of that type.

Mrs. N-, aged thirty-eight, a stout, short woman, of full habit, pregnant some six or seven years after the birth of her last child, was in labour. Matters progressed favourably and naturally until the child's head touched the vagina. At this period I noticed that each pain occasioned considerable flushing of the face and neck, then a wild anxious look, with some incoherence of speech. Anticipating something wrong, I dispatched a messenger, to request the attendance of a friend, who was assisting me, and who shortly arrived. In the meantime I procured to be in readiness a vessel of cold water and vinegar, with a bunch of feathers tied together. The pains increased in frequency, but diminished in force, and no progress was made in the advancement of the labour. In a short time strong convulsions came on. Two women held the patient down, while one of them occasionally dipped the feathers in the vinegar and water, and dashed them against the face and chest of the sufferer. My friend opened a vein in the arm, and at the same time I applied forceps to the child's head, and effected delivery as speedily as possible. About fourteen ounces of blood were abstracted. In a few minutes after the birth of a healthy child, and the extraction of the placenta, the convulsions subsided, and the case became one of ordinary symptoms.

It is not always that medical men can obtain assistance close at hand. The accoucheur cannot bleed the patient, and effect "artificial delivery" at the same moment. He must, therefore, if single-handed, address himself to the mode of treatment which is most important, for in convulsions there is not much time for action. As far as my experience goes, it is most important to expedite the delivery. The cold douche, however, may be used by any bystander, and it certainly has the effect of moving the glottis, and enabling the patient to inspire-a matter of considerable consequence.

I have written this hastily, and currente calamo.

I am, Sir, your obedient servant, and constant reader, Watford, Nov. 1856. SPENCER Pidcock.

\section{SCOTLAND.}

(FROM OUR EDINBURGH CORRESPONDENT.)

UP to the present time fewer students than usual have entered at the University, the number not exceeding 1200 , upwards of 1500 having matriculated at a similar period last year. The medical classes, however, are well filled, and the paucity is apparent only in the literary. The tutorial system is again adopted by Professor Goodsir for the junior pupils of his anatomical class. The classes under Messrs. Turner, Paul, and Edwards cannot be too much praised as a means of imparting sound instruction in this necessary branch of study. The University agricultural class is to be conducted by Dr. George Wilson, Professor Balfour, and Professor Allman: the course is to be divided into two parts, the theoretical and practical ; the former lasting from the present time to the beginning of January, and the latter during the remainder of the course. Dr. Wilson lectures during the present month, Professor Allman during December, and Professor Balfour during January. Mr. J. Chalmers Morton then instructs the class practically upon the subject. (This gentleman was the editor of the "Cyclopædia of Agriculture," and is conversant with both the English and Scotch systems, and recognised as a highly competent authority.)

Nothing is heard of the chair of Military Surgery. When Mr. Cowan questioned the House upon the subject, he was answered that there was plenty of time yet, and that it was not intended to abolish it. Months have passed since then, and it is thought quite time that something more definite should be known upon the subject. Mr. Syme's suggestion for its removal carries with it less weight in the present time of peace, and the success attending the newly-erected chair at Dublin piques those who derived their instruction from the late Sir George Ballingall when they find the chair he held so long un. occupied, and the one of more recent erection surpassing that which was the first established in Great Britain. The recent vacancy as surgeon at the Royal Infirmary has been filled by the election of $\mathrm{Mr}$. Joseph Lister. All the candidates were favourably known, one of them being Mr. Edwards, an assistant of Professor Goodsir. The embarrassments this institution was for some time labouring under are now considerably removed, several handsome donations having recently been given. Amongst others, Mr. Duncan M'Laren presented the entire sum he gained from his famous action with The Scotsman. Whether this be a "conscience salve" or not, it should be eminently calculated to soothe the sensitive feelings of that gentleman, remembering how potent an unguent charity is.

The various Medical Societies have re-assembled, and in most cases addresses have been delivered by their respective presidents. In every instance a vigorous and interesting session seems to be expected.

\section{Atedical alderos.}

Royat College of Surgeons.-The following gentlemen, having undergone the necessary examinations for the Diploma, were admitted members of the College at the meeting of the Court of Examiners on the 2Ist inst.:-

BenNeTt, F'RANCIS I'ON, Birmingham.

Berry, Matthew WeSt, Waringstown, co. Down.

Danier, Peter, Antonisz, Ceylon.

Darling, Wriliam, New York.

Fitzgerald, Edward Ambrose, Calcutta.

Hascemurst, Tromas Wiluiams, Claverley, Shropshire.

Pearse, Reginald Thomas, Clifton, near Bristol.

Richards, Samuer Atiminson, Camberwell.

WISE, Tromas, Beaumont-street, Portland-place.

At the same meeting of the Court, Messrs. Samuer Clift and GEORgE BERINe HILt passed their examinations for NavaI Surgeons. These gentlemen had previously been admitted, the former a member of the London College, the latter of the Edinburgh College, their diplomas bearing date respectively June 9th, 1845, and February, 1846.

Apothecaries' HaLt. - Names of gentlemen who passed their examination in the science and practice of Medicine, and received certificates to practise, on

Thursday, November $20 t h, 1856$.

BIRd, Samier Dougan, Richmond.

Brabazon, Anthony Beaufort, Nottingham. Chavasse, Howard Sidney, Sutton Coldfield. Davies, JoHN, Army.

Haslehust, Thomas Winliams, Shropshire.

Stretton, Samuex, Leicester.

WiLliams, JoH, Wrexham. 